\title{
Reversion rates in a leuB auxotroph of Escherichia coli K-12 correlate with ppGpp levels during exponential growth
}

\author{
Barbara E. Wright and Michael F. Minnick \\ Author for correspondence: Barbara E. Wright. Tel: +1 406243 6676. Fax: +1 4062434184 . \\ e-mail : bewright@selway.umt.edu
}

Division of Biological Sciences, The University of Montana, Missoula, MT 59812-1002, USA
Two isogenic strains of Escherichia coli K-12 differing only in relA, as well as two spoT transductants of the relA- strain, were examined with respect to ppGpp levels and reversion rates of a leuB- allele under nine different conditions. A positive correlation was established between reversion rates and the steady-state concentration of ppGpp during exponential growth. The leuB genes from two leuB- strains (isogenic except for relA) were cloned and sequenced and found to contain a single mutation, namely, a C-to-T transition at nucleotide 857 . This mutation resulted in a serine-to-leucine substitution at amino acid residue 286 of the LeuB protein. PCR products that encompassed the leuB lesion were generated from 53 revertants and then sequenced. Of these revertants, 36 were found to contain nucleotide substitutions that would result in a serine (wild type), valine or methionine at amino acid residue 286 of LeuB, and nearly all of them exhibited generation times similar to wild type. Seventeen of the analysed revertants were found to be suppressors that retained the encoded leucine at residue 286. The majority of the suppressor mutants exhibited generation times that were significantly longer than wild type.

Keywords : stringent response, ppGpp, mutation rates, starvation

\section{INTRODUCTION}

The complex of metabolic events triggered by amino acid starvation in Escherichia coli is called the stringent response (reviewed by Cashel \& Rudd, 1987). This response is marked by an immediate burst in the accumulation of $\mathrm{ppGpp}$, which acts to reduce the rate of rRNA and tRNA synthesis and to stimulate the rate of synthesis of 'nutritional stress' proteins such as amino acid biosynthetic enzymes. The synthesis of ppGpp is primarily controlled by ppGpp synthase I (the relA gene product) and requires mRNA, ribosomes and codonspecified uncharged tRNA bound in the ribosomal A site. The activity of the ppGpp degradative enzyme, (p)ppGpp 3'-pyrophosphohydrolase (the spoT gene product) is also regulated by starvation conditions (Fiil et al., 1972; Gallant et al., 1972). This enzyme, known as ppGpp synthase II, may be bifunctional, i.e. capable of catalysing either synthesis or degradation of ppGpp (Fehr \& Richter, 1981; Xiao et al., 1991). Clearly, an increase in ppGpp levels can result from a higher rate of synthesis or from an inhibition of degradation. Evidence indicates that cellular ppGpp levels are regulated by the charging of total tRNA species, as a function of the intracellular concentrations of all amino acids (Friesen et al., 1975). The ppGpp concentration adjusts the levels of biosynthetic enzymes relative to the supply of all the amino acids in the external environment, whereas operon-specific attenuator mechanisms respond to the need for specific amino acids (Stephens et al., 1975; Winkler et al., 1978). In Salmonella typhimurium regulation of the expression of the his operon by ppGpp is independent of the operon-specific attenuator mechanism that does not involve ppGpp. There is a good correlation between his operon expression and ppGpp levels under steady-state growth conditions (Rudd et al., 1985; Shand et al., 1989; Stephens et al., 1975; Winkler et al., 1978, 1979) and various lines of in vivo and in vitro evidence indicate that the effect on bis expression occurs primarily by transcription initiation at the his promoter (Riggs et al., 1986; Stephens et al., 1975). The leu operon appears to be regulated like the his operon, i.e. by both attenuation (Burns et al., 1966) and ppGpp, as indicated in this and related studies (Wright, 1996, 1997).

Recent investigations (Wright, 1996) have examined the 
effect of the stringent response on reversion rates of point mutations in two isogenic strains of $E$. coli differing only in relA. Reversion rates of the $l e u B^{-}$and argH $\mathrm{H}^{-}$alleles in strain CP78 were significantly higher than in the isogenic counterpart, CP79 (relA2). A positive correlation was established between reversion rates and the synthesis of ppGpp during the classical stringent response that occurs within seconds as growth deviates from the exponential phase in amino-acidlimited cultures. The distribution of revertants in mutation rate experiments indicated that most of the mutations occurred during this period of diminishing growth, i.e. the time between the end of exponential growth and the cessation of growth. However, mutations also occurred during exponential growth, especially when the rate of exponential growth was inhibited, for example by serine hydroxamate, which provokes the stringent response as a competitive inhibitor of seryl-tRNA (Cashel \& Rudd, 1987; Metzgar et al., 1989; Shand et al., 1989). Under these conditions the mean revertant colony counts on positive plates were abnormally high (data not shown), indicating that the mutation occurred during the exponential growth phase of that culture. According to Cashel \& Rudd (1987), effects associated with the classical stringent response also operate during exponential growth to a lesser extent and all relate to the metabolism of ppGpp. Therefore, one goal of the present investigation was to document a possible correlation between mutation rates and the steady-state concentrations of ppGpp during exponential growth, through the use of various strains and culture conditions that produce different levels of cellular ppGpp. To this end, two spoT alleles known to accumulate high ppGpp levels were transduced into CP79 and these strains were grown with and without serine hydroxamate. The CP78 strain was also grown with $\gamma$-glutamyl leucine, which apparently served as a poor source of leucine, thereby imposing leucine starvation during exponential growth. The results indicate a positive correlation between reversion rates and ppGpp concentrations during exponential growth.

Another goal of these investigations was to sequence and define the lesion in the leuB mutant gene as well as to sequence its revertants, as reversion rates of this mutant allele are being used as a model system to test the hypothesis that enhanced mutation rates result from derepression provoked by amino acid starvation and ppGpp accumulation (Wright, 1997).

\section{METHODS}

Strains. The genotypes of the $E$. coli strains used in this study are summarized in Table 1 . To obtain strains with altered ppGpp levels, spoT alleles were transduced using P1 vir into the CP79 relA2 strain, producing strains (Table 1) that grew more slowly than the CP79 relA2 host. Strains with such spoT alleles are known to grow more slowly in relA1 backgrounds than in $\Delta$ rel $A$ hosts, and cells with null alleles in both the $r e l A$ and spoT genes are multiple auxotrophs (Sarubbi et al., 1988; Xiao et al., 1991). This suggested that relA2 is not a deletion but is a leaky mutation, like relA1. To confirm this, relA2 was replaced in the CP79 $\Delta$ spoT207 strain by $\Delta$ relA251 (Table 1).
As suspected, a multiple auxotroph was formed, confirming that relA2 is similar to relA1.

Growth conditions for mutation rate determinations. Cells were grown at $37^{\circ} \mathrm{C}$ for $42-48 \mathrm{~h}$ in minimal medium consisting of $40 \mathrm{mM}$ glycerol, $50 \mathrm{mM}$ sodium phosphate buffer, $\mathrm{pH} 6 \cdot 5,1.0 \mathrm{~g}\left(\mathrm{NH}_{4}\right\rangle_{2} \mathrm{SO}_{4} \mathrm{I}^{-1}, 1.0 \mathrm{~g} \mathrm{MgSO}_{4} \mathrm{l}^{-1}, 5 \cdot 0 \mathrm{mg}$ thiamine $\mathrm{l}^{-1}, 1.0 \mathrm{mM}$ threonine, $0.15 \mathrm{mM}$ leucine, $0.3 \mathrm{mM}$ arginine and $0.3 \mathrm{mM}$ histidine. When growth was limited by leucine, the amino acid was present at $0.025 \mathrm{mM} ; \gamma$-glutamyl leucine was used at $0.06 \mathrm{mM}$. Cells grown in the presence of $1.5 \mathrm{mM}$ serine hydroxamate and excess leucine $(0.04 \mathrm{mM})$ were washed prior to plating, to prevent growth on the plates due to carry over of leucine. The 'zero' method of Luria \& Delbrück (1943) was used to determine mutation rates. In a typical experiment, a large culture inoculated with cells from a 7-h-old nutrient agar plate at a cell density of about $5 \times 10^{4} \mathrm{ml}^{-1}$ was prepared and $1.5 \mathrm{ml}$ aliquots were distributed into 402 -cm-diam, test tubes which were shaken at a $45^{\circ}$ angle at $37^{\circ} \mathrm{C}$ for $24-48 \mathrm{~h}$, depending upon the growth rate of the strain. Each entire culture was then spread onto selective plates. Tenfold dilutions in buffered saline were made of a few identical cultures and the $\mathrm{OD}_{550}$ value read to select two typical cultures for appropriate dilutions to determine total viable cell numbers on nutrient agar plates. If the two viable counts differed by more than $25 \%$, the experiment was discarded. The equivalence of viable counts and total cell numbers was assured based on a standard curve comparing the $\mathrm{OD}_{550}$ reading to viable counts using exponentially growing cells. Revertant colonies first appear on selective plates about $40 \mathrm{~h}$ after plating and final counts were made at 65-78 h. Mutation rates were estimated by the 'zero' method (Luria \& Delbrück, 1943) according to the expression MR = $(-\ln 2)\left(\ln P_{0} / N\right)$, where $P_{0}$ is the proportion of cultures with no revertants, and $N$ is the total number of cells per culture.

Determination of steady-state levels of ppGpp. Cultures were grown at $37^{\circ} \mathrm{C}$ in the above medium with the exceptions that (1) leucine was present at $0.1 \mathrm{mM}$, to achieve exponential growth during the ${ }^{32} \mathrm{P}$ labelling period, and (2) the phosphate buffer was replaced by $40 \mathrm{mM}$ MES buffer, $\mathrm{pH} 6.5$, and the $\mathrm{KH}_{2} \mathrm{PO}_{4}$ concentration was lowered to $0.5 \mathrm{mM}$ to dilute added ${ }^{32} \mathrm{P}$ to a minimal extent. To analyse ppGpp concentration during exponential growth, the $16 \mathrm{~h}$ cultures were centrifuged and resuspended to an $\mathrm{OD}_{550}$ of $0.03-0.25$ (depending on their growth rate) in fresh medium with or without $1.5 \mathrm{mM}$ serine hydroxamate or substituting $0.06 \mathrm{mM}$ $\gamma$-glutamyl leucine for $0 \cdot 1 \mathrm{mM}$ leucine. Aliquots $(1 \mathrm{ml})$ were removed and their phosphate concentrations determined (Sigma diagnostics, procedure no. 670). Aliquots $(1.0-1.5 \mathrm{ml})$ were removed to $20 \mathrm{ml}$ glass vials and ${ }^{32} \mathrm{P}$ (New England Nuclear) added to a final concentration of $100-300 \mu \mathrm{Ci} \mathrm{m} l^{-1}$ $\left(3.7 \times 10^{6}-1.1 \times 10^{7} \mathrm{~Bq} \mathrm{ml}^{-1}\right)$. Aliquots $(15 \mathrm{ml})$ were transferred to nephelo culture flasks and $\mathrm{OD}_{550}$ was monitored every 30-60 min to determine the rate of exponential growth. After $4 \mathrm{~h}$ of labelling with ${ }^{32} \mathrm{P}$, samples were removed and prepared for polyethylenimine (PEI) cellulose chromatography. To ensure that the ppGpp pool was saturated with ${ }^{32} \mathrm{P}$, a second sample was removed for analysis at $4.5 \mathrm{~h}$. Regardless of the generation time of the culture, the values at $4.5 \mathrm{~h}$ and $4.0 \mathrm{~h}$ were comparable, indicating saturation of the ppGpp pool. Aliquots of each culture $(50 \mu \mathrm{l})$ were pipetted

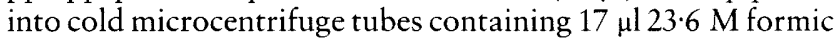
acid (final concn $6 \mathrm{M}$ ), mixed and freeze-thawed twice in dry ice/ethanol and a $37^{\circ} \mathrm{C}$ water bath. After centrifugation, 2 and $5 \mu \mathrm{l}$ aliquots were spotted onto washed PEI cellulose plates. A $5 \mu \mathrm{l}$ aliquot of $10 \mathrm{mM}$ GTP prepared in the same manner was spotted as a standard. Ascending chromato- 
Table 1. Genotypes of E. coli strains used

\begin{tabular}{|c|c|c|}
\hline Strain & Genotype & Source \\
\hline CP78 & $\begin{array}{l}\mathrm{F}^{-} \text {thr-1 leuB6 his65 argH46 thi-1 ara-13 } \\
\text { gal-3 malA1 }\left(\lambda^{\mathrm{R}}\right) \text { xyl-7 mtl-2 tonA2 } \\
\text { supE44? }\end{array}$ & E. coli Genetic Stock Center, Yale, USA \\
\hline CР79 & As CP78, but relA2 & E. coli Genetic Stock Center, Yale, USA \\
\hline CP79 $\Delta s p o T 207$ & 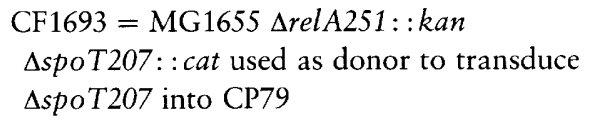 & This study \\
\hline CP79 spoT203 & $\begin{array}{l}\text { CF3042 = CF930 = N99 relA1 zib563: :Tn10 } \\
\text { (spoT203) used as donor to transduce } \\
\text { spoT203 into CP79 }\end{array}$ & This study \\
\hline CP79 $\Delta s p o T 207 \Delta r e l A 251$ & $\begin{array}{l}\text { CF1652 = MG1655 } \Delta \text { relA251: : kan used as } \\
\text { donor to transduce } \Delta \text { relA251 into CP79 } \\
\text { AspoT207 }\end{array}$ & This study \\
\hline $\mathrm{CF} 1693=\mathrm{MG} 1655$ & ArelA251::kansspoT207: :cat & M. Cashel (Xiao et al., 1991) \\
\hline CF3042 = CF930 = N99 & relA1zib563: :Tn10 (spoT203) & M. Cashel (Xiao et al., 1991) \\
\hline $\mathrm{CF} 1652=\mathrm{MG} 1655$ & $\Delta r e l A 251:$ : kan & M. Cashel (Xiao et al., 1991) \\
\hline
\end{tabular}

graphy in $1.5 \mathrm{M} \mathrm{KH}_{2} \mathrm{PO}_{4}, \mathrm{pH} 3.4$, was run at $5{ }^{\circ} \mathrm{C}$ until the solvent front was $16 \mathrm{~cm}$ from the origin. The radioactive spots were located by autoradiography on Kodak X-Omat film AR (Wright, 1996). The radioactive areas corresponding to $p p G p p$ were cut off the plate, wetted with $0.25 \mathrm{ml}$ water and counted in $5 \mathrm{ml}$ cytoscint (ICN). The concentration of ppGpp in $\left[\mathrm{pmol}\left(\mathrm{OD}_{550} \mathrm{unit}^{-1}\right]\right.$ was based on the specific radioactivity of the medium phosphate.

DNA manipulation. Chromosomal DNA from E. coli was isolated by the methods of Ausubel et al. (1989). Approximately $1 \mathrm{ng}$ purified DNA was PCR amplified using a PCR Core Kit and Taq polymerase according to the manufacturer's instructions (Perkin Elmer Cetus). PCR was done by 30 cycles of $94{ }^{\circ} \mathrm{C}(1 \mathrm{~min}), 55^{\circ} \mathrm{C}(2 \mathrm{~min})$ and $72{ }^{\circ} \mathrm{C}(1.5 \mathrm{~min})$. Primers for amplifying the entire $l e u B$ gene for cloning were based upon the nucleotide sequence of Kirino et al. (1994) (GenBank accession no. D17631) and included 5' TTTAAGCTTCAACGAAAACAACAAGGAAACCGTGTG (primer 1) and 5' TTTTCTAGAACAATTTTTCGTATAACGTCTTAGCC (primer 2). For screening revertants, PCR amplification of a 416 bp region encompassing the encoded Ser-286 $\rightarrow$ Leu lesion of leuB (nt 856-858) was accomplished by using 5' GATCCATCACAGTTTGACGTTCTGC (primer 3) and primer 2. Primers were synthesized with an Applied Biosystems (ABI) model 394 DNA synthesizer at The University of Montana Molecular Biology Facility.

PCR products containing the full-length $l e u B$ gene were excised from ethidium-bromide-stained agarose gels and then purified using GeneClean II according to the manufacturer's instructions (Bio101). The DNA was blunt-ended with Klenow fragment and then cloned into the SmaI restriction site of pUC19 (Yanisch-Perron et al., 1985) by standard protocol (Sambrook et al., 1989). E. coli DH5 $\alpha$ was then transformed with the resulting plasmids by the methods of Chung et al. (1985). Transformants were initially screened for recombinant DNA by blue/white screening on LB medium containing ampicillin $\left(0 \cdot 1 \mathrm{mg} \mathrm{m}^{-1}\right)$, IPTG (Gibco BRL) and Bluo-Gal (Gibco BRL). Plasmid DNA from the white colonies was obtained by alkaline minipreps (Sambrook et al., 1989), restriction-endonuclease-digested and then analysed for insert content on ethidium-bromide-stained agarose gels.
Nucleotide sequence analyses were done by the methods of Tracy \& Mulcahy (1991) on an ABI automated nucleic acid sequencer (ABI; model 373A). Sequencing-grade templates were prepared by a Midi-Prep Kit (Qiagen) for leuBcontaining plasmids or by GeneClean (Bio101) for the $416 \mathrm{bp}$ PCR products from agarose gels. Computer analysis of the sequences was performed using PCGENE 6.8 software (Intelligenetics).

\section{RESULTS}

\section{Growth rate determinations}

Fig. 1 compares the exponential growth rates of different strains under the various culture conditions used in this investigation. The growth rates ranged from the lowest generation time of $100 \mathrm{~min}$ for strains CP78 and CP79 to the highest generation time of $652 \mathrm{~min}$ for CP79 in the presence of serine hydroxamate. In the latter case, the low rate of growth was followed for more than $10 \mathrm{~h}$ and did not deviate from linearity. The mean values of replicate determinations are summarized in Table 3.

\section{Mutation rate determinations}

$l e u B^{-}$reversion rates of the two spo $T$ strains grown with and without serine hydroxamate are shown in Table 2. In the absence of serine hydroxamate, the $\Delta s p o T$ strain exhibited a reversion rate approximately threefold higher than its parent strain, CP79 (Tables 2 and 3). The reversion rate of CP79 2 spoT207 was only slightly stimulated by serine hydroxamate, in contrast to strain CP79 (Table 3). The reversion rate of the CP79 spo T203 strain was approximately 10 -fold higher than that of its parent strain, and was nearly halved by serine hydroxamate (Tables 2 and 3).

To find other conditions that might alter ppGpp levels and reversion rates in the $l e u B$ auxotrophs, various leucine derivatives were examined for their ability to 


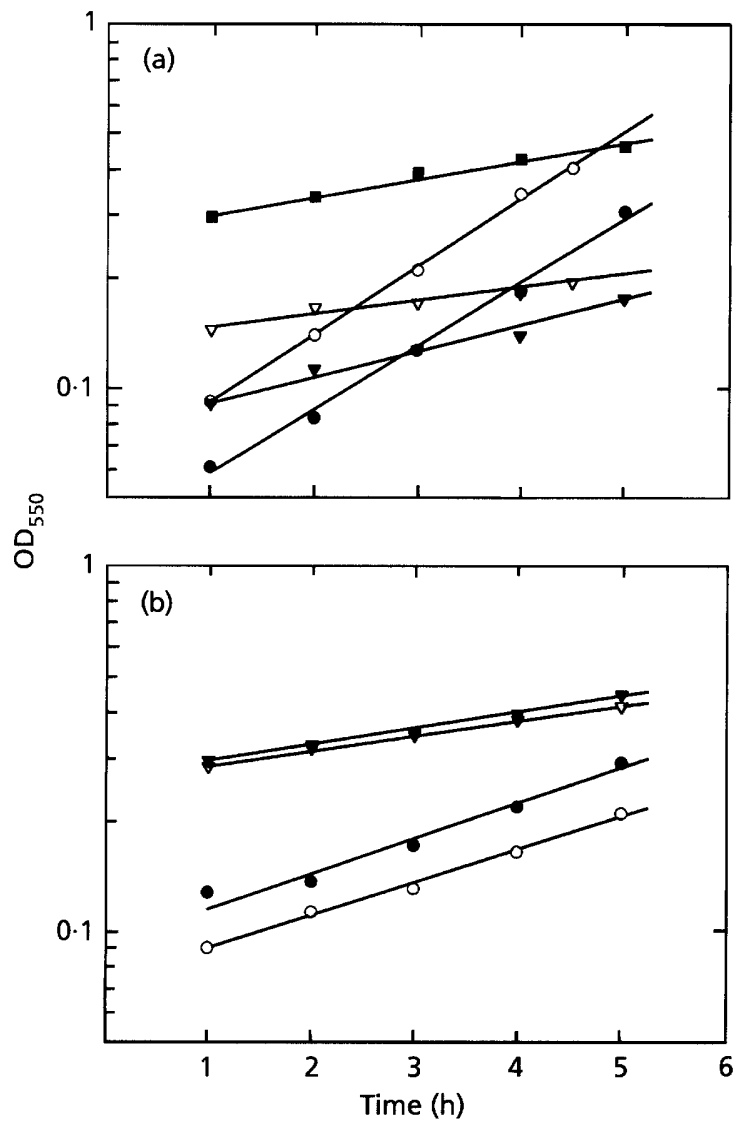

Fig. 1. Exponential growth curves for the strains and culture conditions used in determining the concentration of ppGpp under steady-state conditions. (a) O CP78; $\nabla, C P 78+1.5 \mathrm{mM}$ serine hydroxamate; $\square, C P 78+0.06 \mathrm{mM} \gamma$-glutamyl leucine; $O$, $\mathrm{CP79} ; \nabla, \mathrm{CP} 79+1.5 \mathrm{mM}$ serine hydroxamate. (b) $0, \mathrm{CP79}$ $\Delta$ spoT207; $\nabla, C P 79 \Delta$ spoT207+1.5 mM serine hydroxamate; $O$, CP79 spoT203; $\nabla$, CP79 spoT203 $+1.5 \mathrm{mM}$ serine hydroxamate.

supply leucine at a low rate, thereby inducing a state of partial starvation and provoking the stringent response. Replacing leucine with the peptide $\gamma$-glutamyl leucine significantly lowered the growth rate of strain CP78 (Fig. 1). When grown in the presence of this peptide, the reversion rate of CP78 was about fourfold higher than in the presence of limiting leucine (Tables 2 and 3).

\section{ppGpp levels}

The steady-state levels of ppGpp were determined during exponential growth in the strains and under the conditions summarized in Fig. 1 and Table 3. Fig. 2 shows the mutation rates plotted against both the concentration of $p p G p p$ and the generation time. The medium used for measuring ppGpp levels was essentially the same as that used in mutation rate experiments, except that the leucine concentration was necessarily in excess during exponential growth. Leucine was limiting (unless cell growth was inhibited) in mutation rate determinations to achieve a low cell density such that a significant fraction of the cultures would have no revertants. This was necessary to calculate rates by the 'zero' method (Luria \& Delbrück, 1943). MES buffer was used in the ppGpp experiments because phosphate levels had to be lowered to minimally dilute the ${ }^{32} \mathrm{P}$ added. In separate experiments (not shown) it was found that mutation rates using medium with the MESphosphate buffer were comparable to those in phosphate buffer.

Other investigators measuring ppGpp levels in vivo have labelled at least one (Friesen et al., 1975) or two (Lagosky \& Chang, 1980) generations with ${ }^{32} \mathrm{P}$ prior to sampling. In the experiments reported here, labelling with ${ }^{32} \mathrm{P}$ occurred for $4 \mathrm{~h}$, which was equivalent to $0.4-2.5$ generation times, depending upon the strain and the medium employed (Fig. 1). To ensure that the ppGpp pool was equilibrated with the $\mathrm{P}_{i}$ pool, samples were taken again at $4.5 \mathrm{~h}$. In every case, the 4 and $4.5 \mathrm{~h}$ samples were indistinguishable, indicating that the small metabolite pools were turning over rapidly regardless of generation time. As the ppGpp pools were saturated, their concentration could be based on the specific radioactivity of the phosphate in the medium.

\section{Revertant colony sizes}

Colony counts on 20 plates from a typical 40 -culture mutation rate experiment are shown in Table 4 (see Methods). Because growth was limited by threonine, the $\mathrm{leu}^{+}$revertants had no selective advantage. Colony counts at $66 \mathrm{~h}$ after plating were used to calculate mutation rates. At least $70 \%$ of these proved to be true revertants, regardless of the strain in which they arose

\section{Table 2. leuB reversion rates}

The values given are the means of at least four independent mutation rate determinations. For experimental conditions and for the method of determining mutation rates, see Methods.

\begin{tabular}{|c|c|c|c|c|c|}
\hline & \multicolumn{2}{|c|}{ CP79 $\Delta s p o T 207$} & \multicolumn{2}{|c|}{ CP79 spoT203 } & \multirow{2}{*}{$\begin{array}{c}\text { CP78 } \\
\begin{array}{c}\text { Growth on } \\
\gamma \text {-glutamyl leucine }\end{array}\end{array}$} \\
\hline & $\begin{array}{l}\text { Leucine- } \\
\text { starved }\end{array}$ & $\begin{array}{l}\text { Seryl-tRNA- } \\
\text { starved }\end{array}$ & $\begin{array}{l}\text { Leucine- } \\
\text { starved }\end{array}$ & $\begin{array}{l}\text { Seryl-tRNA- } \\
\text { starved }\end{array}$ & \\
\hline $10^{8} \times$ Total cell number & $2 \cdot 8 \pm 0.76$ & $0 \cdot 31 \pm 0 \cdot 12$ & $0 \cdot 80 \pm 0 \cdot 14$ & $1 \cdot 85 \pm 0.38$ & $1 \cdot 25 \pm 0.18$ \\
\hline$P_{0}$ (no. negative plates/total) & $0.79 \pm 0.03$ & $0.96 \pm 0.02$ & $0.76 \pm 0.04$ & $0.69 \pm 0.08$ & $0.33 \pm 0.07$ \\
\hline $10^{9} \times$ Mutation rate & $0 \cdot 60 \pm 0 \cdot 11$ & $1.03 \pm 0.09$ & $2 \cdot 5 \pm 0.62$ & $1 \cdot 3 \pm 0 \cdot 32$ & $6 \cdot 4 \pm 1 \cdot 7$ \\
\hline
\end{tabular}


Table 3. Relationship of mutation rates to levels of ppGpp and generation time

\begin{tabular}{|c|c|c|c|}
\hline Strain and condition ${ }^{*}$ & $\begin{array}{l}10^{9} \times \text { Mutation } \\
\text { rate }\end{array}$ & $\begin{array}{c}\text { ppGpp concn } \\
{\left[\text { pmol }(\text { OD unit })^{-1}\right] \dagger}\end{array}$ & $\begin{array}{l}\text { Generation } \\
\text { time }(\min ) \neq\end{array}$ \\
\hline $\mathrm{CP} 78$ & $1.5 \pm 0.48 \mathbb{S}$ & $327 \pm 30$ & $100 \pm 6$ \\
\hline $\mathrm{CP} 78+\mathrm{SH}$ & $4.9 \pm 0.37 \$$ & $479 \pm 40$ & $212 \pm 39$ \\
\hline CP78 $+\gamma$-Glu-Leu & $6 \cdot 4 \pm 1 \cdot 7$ & $753 \pm 81$ & $630 \pm 90$ \\
\hline СР79 & $0 \cdot 22 \pm 0.08 \$$ & $234 \pm 17$ & $102 \pm 8$ \\
\hline $\mathrm{CP} 79+\mathrm{SH}$ & $4 \cdot 4 \pm 2 \cdot 1 \$$ & $391 \pm 29$ & $652 \pm 124$ \\
\hline CP79 $\Delta$ spoT207 & $0 \cdot 60 \pm 0 \cdot 11$ & $267 \pm 77$ & $156 \pm 22$ \\
\hline $\mathrm{CP} 79 \Delta s p o T 207+\mathrm{SH}$ & $1.0 \pm 0.09$ & $395 \pm 81$ & $371 \pm 45$ \\
\hline CP79 spoT203 & $2 \cdot 5 \pm 0.62$ & $335 \pm 54$ & $207 \pm 38$ \\
\hline $\mathrm{CP} 79$ spoT $203+\mathrm{SH}$ & $1 \cdot 3 \pm 0 \cdot 32$ & $321 \pm 60$ & $494 \pm 30$ \\
\hline
\end{tabular}

*SH, serine hydroxamate; $\gamma$-Glu-Leu, $\gamma$-glutamyl leucine.

+ Means of four determinations $\pm S D$; see Methods for details.

$\ddagger$ Means of four to eight determinations $\pm S D$; see Methods for details.

\$Taken from Wright (1996).

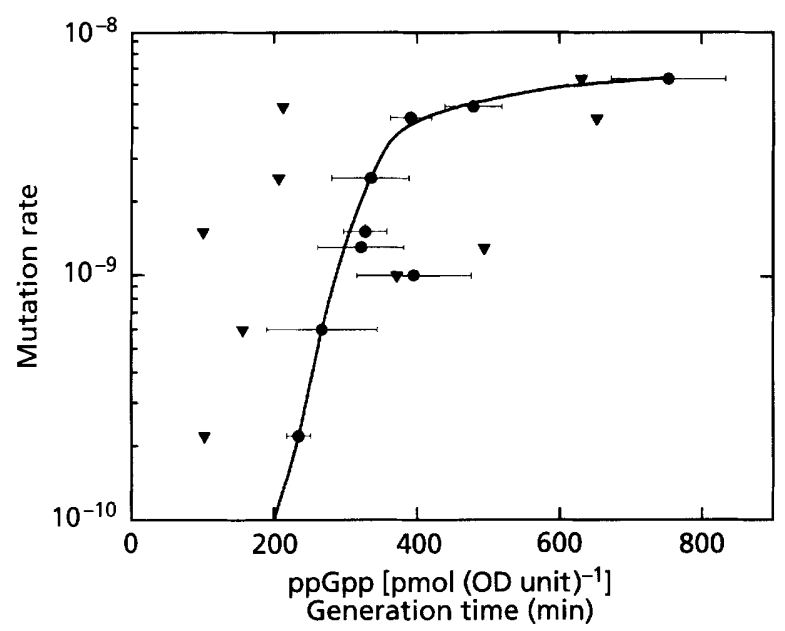

Fig. 2. Reversion rate of leuB under different conditions (see Table 2 and Fig. 1) plotted against the generation time $(\boldsymbol{A})$ and against the ppGpp concn (O) during exponential growth. Bars indicate SD.

(see below). Very small colonies were rarely seen at that time. However, they began to appear after $90 \mathrm{~h}$ incubation and in general stopped appearing after about $138 \mathrm{~h}$. The variance of the small colonies at $162 \mathrm{~h}$ was $4.8 \times 10^{4}$, compared to the mean of 115 , suggesting that these small colonies were the progeny of slow-growing clones that arose in the liquid cultures and thereafter grew slowly on the plates. In other words, they were not post-plating mutations. Nucleotide sequence analyses indicated that they were suppressor mutants.

\section{Cloning and sequence analysis}

The sequence of the leuB gene, which encodes the enzyme $\beta$-isopropyl malate dehydrogenase (EC 1.1.1.85), has been determined (Kirino et al., 1994;
Table 4. $\mathrm{eu}^{+}$revertants from threonine-starved cultures

CP78 cultures were grown in the presence of $0.15 \mathrm{mM}$ leucine and limiting threonine $(0.08 \mathrm{mM})$. Each culture was washed prior to plating on minimal agar lacking leucine (see Methods). Cell density at the time of plating was $1.3 \times 10^{8} \mathrm{ml}^{-1}$.

Abbreviations: L, large colony size; $\mathrm{S}$, small colony size.

\begin{tabular}{|c|c|c|c|c|c|c|c|c|c|c|c|c|}
\hline \multirow{2}{*}{$\begin{array}{l}\text { Time }(h): \\
\text { Plate no. }\end{array}$} & \multicolumn{2}{|c|}{42} & \multicolumn{2}{|c|}{66} & \multicolumn{2}{|c|}{90} & \multicolumn{2}{|c|}{114} & \multicolumn{2}{|c|}{138} & \multicolumn{2}{|c|}{162} \\
\hline & $\mathbf{L}$ & $\mathbf{S}$ & $\mathrm{L}$ & $S$ & $\mathbf{L}$ & $S$ & L & $\mathbf{S}$ & $\mathrm{L}$ & $S$ & $\mathrm{~L}$ & $S$ \\
\hline 1 & & & & & & & & 160 & & 228 & & 228 \\
\hline 2 & & & & & & & & 4 & & 5 & & 5 \\
\hline 3 & & & & & & 1 & & 104 & & 104 & & 104 \\
\hline 4 & & & & & & & & 15 & & 92 & & 92 \\
\hline 5 & & & & & & & & 31 & & 211 & & 211 \\
\hline 6 & & & & & & & & 2 & & 8 & & 18 \\
\hline 7 & & & & & & & & & & 3 & & 3 \\
\hline 8 & 2 & & 2 & & 2 & 1 & 2 & 42 & 2 & 84 & 2 & 84 \\
\hline 9 & & & & & & & & 640 & & 640 & & $\sim 1000$ \\
\hline 10 & & & & & & 2 & & 2 & & 5 & & 5 \\
\hline 11 & & & & & & 1 & & 6 & & 150 & & 150 \\
\hline 12 & & & 1 & & 1. & 1 & 1 & 9 & 1 & 23 & 1 & 23 \\
\hline 13 & & & & & & 1 & & 3 & & 7 & & 9 \\
\hline 14 & & & 2 & & 2 & 3 & 2 & 5 & 2 & 6 & 2 & 6 \\
\hline 15 & & & & & & & & 15 & & 27 & & 37 \\
\hline 16 & & & & & & 1 & & 12 & & 13 & & 13 \\
\hline 17 & & & 1 & & 1 & 1 & 3 & 172 & 3 & 172 & 3 & 172 \\
\hline 18 & & & & & & 2 & & 3 & & 19 & & 37 \\
\hline 19 & & & & & & 1 & 1 & 24 & 1 & 60 & 1 & 63 \\
\hline 20 & & & & & 1 & 1 & 1 & 10 & 1 & 46 & 1 & 46 \\
\hline
\end{tabular}

GenBank accession no. D17631). Sequence analysis of the cloned $l e u B$ genes from the $l e u B^{-}$mutants CP78 and CP79 revealed complete nucleotide sequence identity to the published leuB gene except for C-to-T transitions at nucleotide 857 . This point mutation would result in a 
Table 5. Sequence of the leuB- mutants and revertants at nt 856-858

\begin{tabular}{|c|c|c|}
\hline $\begin{array}{l}\text { Single base } \\
\text { Sequence }\end{array}$ & $\begin{array}{l}\text { substitution } \\
\text { Predicted } \\
\text { amino acid }\end{array}$ & $\begin{array}{l}\text { observed } \\
86\end{array}$ \\
\hline TTG & Leucine & leu $B^{-}$mutant \\
\hline TCG & Serine & Wild-type E. coli leuB \\
\hline GTG & Valine & Phenotypically wild type \\
\hline ATG & Methionine & Phenotypically wild type \\
\hline \multicolumn{3}{|c|}{ Predicted amino acid residue 286 in true revertants } \\
\hline \multicolumn{2}{|l|}{ Strain } & Amino acid (no. observed) \\
\hline \multicolumn{2}{|l|}{ CP78 } & Ser $(7), \operatorname{Val}(8)$ \\
\hline \multicolumn{2}{|l|}{ CP79 } & Ser $(6), \operatorname{Val}(1)$ \\
\hline \multirow{2}{*}{\multicolumn{2}{|c|}{$\begin{array}{l}\text { CР79 } \Delta s p o T 207 \\
\text { CP79 spoT203 }\end{array}$}} & $\operatorname{Ser}(1), \operatorname{Val}(6)$ \\
\hline & & Ser (2), Val (3), Met (2) \\
\hline
\end{tabular}

serine-to-leucine substitution at amino acid residue 286 of the LeuB protein. The sequence of the leuB $B^{-}$mutant gene in the region of the mutation is shown in Table 5 and the possible single base substitutions in this codon and the corresponding amino acids are also summarized. Base substitutions encoding serine, valine and methionine were all observed among the revertants; the other possibilities (tryptophan or phenylalanine) were never observed, perhaps because they are too bulky to replace serine. Of the 36 true revertants, two had generation times significantly longer than wild-type cells. Revertants containing the Met-286 substitution were unique to E. coli strain CP79 spoT203. Of the 17 suppressors that were sequenced (i.e. an encoded Leu remained at amino acid residue 286), five had generation times comparable to wild type.

\section{DISCUSSION}

To study the relationship between mutation rates and the stringent response, two isogenic multiple auxotrophs were chosen, namely CP78 and CP79 (Table 1 ). These strains differ only in relA and have been widely used in investigations of the stringent response over the past 20 years. The leuB allele was chosen for intensive study since (a) the leuB gene has been sequenced (Kirino et al., 1994), (b) revertant colonies appearing after $2 \mathrm{~d}$ were all of large, uniform size and (c) the reversion rate was conveniently low for using the 'zero' method of calculating mutation rates (Luria \& Delbrück, 1943). This is preferable to the 'average' method (Lea \& Coulson, 1949) which does not measure the number of initial mutational events and is subject to various artifacts (Stewart et al., 1990). The validity of the 'zero' method depends only upon the survival of each revertant, which has been demonstrated in reconstruction experiments (Wright, 1996). Since the reversion rate depends upon the fraction of plates without colonies, the parental mutant may be grown in medium which may or may not select for the revertants (Ryan, 1955). To obtain a significant fraction of 'zero' plates, the final cell concentration is adjusted by the concentration of a required amino acid, or of an inhibitor such as serine hydroxamate.

Using a series of spoT mutant alleles, an inverse linear relationship was found between steady-state rates of growth and ppGpp levels (Sarubbi et al., 1988). The ppGpp concentrations and the reversion rates of $l e u B^{-}$ in the two CP79 spoT strains (Table 2) were higher than in CP79. This would be expected as a result of the blocking of ppGpp degradation by ppGpp synthase II. It is significant that serine hydroxamate did not affect ppGpp levels or mutation rates in these spoT transductants as much as it did in CP79, suggesting that the site of action of this inhibitor is ppGpp degradation. Growth on the $\gamma$-glutamyl leucine peptide had the largest effect on ppGpp levels and mutation rates in CP78 (Table 3). Use of this peptide as a substitute for leucine in leu auxotrophs is assumed to be comparable to the use of histidinol or formyl histidine as substitutes for histidine in his auxotrophs (Ames \& Garry, 1959; Blasi \& Bruni, 1981). Growth on either of these poor sources of histidine imposes partial starvation and provokes the stringent response; genes for the synthetic enzymes are derepressed, which could then result in increased rates of mutation. During exponential growth the most striking effects on ppGpp accumulation and reversion rates in strains CP78 and CP79 were seen when derepression and a low rate of cell division were both maintained due to the presence of $1.5 \mathrm{mM}$ serine hydroxamate or $\gamma$-glutamyl leucine (Fig. 1). In $S$. typhimurium the addition of $2.0 \mathrm{mM}$ serine hydroxamate inhibited growth and provoked an increase in ppGpp levels and his operon expression with a similar time course (Shand et al., 1989).

Two general classes of $\mathrm{leu}^{+}$revertants were observed: (a) true revertants, with base substitutions encoding serine (wild type), valine or methionine with generation times of about $100 \mathrm{~min}$; and (b) suppressors, which retained the Leu-286 residue of the parental leuB mutant and usually had generation times in excess of $200 \mathrm{~min}$. The distribution of these two classes of revertants suggests that they may arise by different mechanisms. As discussed above, the true revertants appeared with a low variance towards the end of growth when ppGpp levels showed a significant, transient increase from basal levels (Lazzarini et al., 1971; Wright, 1996). Suppressor mutants originated throughout the growth phase of the liquid cultures and appeared with a high variance after 4-7 d incubation on the selective plates. These observations suggest that the mutations resulting in true reversions may have been influenced by the stringent response to a greater extent than the suppressor mutations.

Genes undergoing transcription are uniquely susceptible to mutations (Cordaro \& Balbinder, 1967; Datta \& Jinks-Robertson, 1995； Davis, 1989; Fitch, 1982; Herman \& Dworkin, 1971; Lindahl \& Nyberg, 1972, 
1974; Savić \& Kanazir, 1972; Siebenlist et al., 1980; Singer \& Kusmierck, 1982; see also Wright, 1997) and repair (Hanawalt \& Mellan, 1993; Selby \& Sancar, 1994). Cashel \& Rudd (1987) believe that all effects of the stringent response can be attributed to the metabolism of ppGpp, and the extensive literature on this subject supports our conclusion that ppGpp stimulates transcription of the leu operon, which in turn affects reversion rates due to an increase in the concentration of single-stranded DNA. Mutation rates have now been correlated with ppGpp levels during exponential growth (Fig. 2) as well as during the transition period between the end of exponential growth and stationary phase (Wright, 1996). Studies in progress will examine the correlation between mutation rates and enzyme and mRNA levels of the leu operon. About 500 pmol ppGpp appears to be optimal to enhance reversion rates of the leu $B^{-}$allele (Fig. 1). It should be possible to determine whether this level of ppGpp is also optimal for the de novo synthesis of the enzymes encoded by the leu operon in an in vitro transcription-translation system. If so, this would further strengthen the correlation between the stringent response, transcription and mutation rates.

\section{ACKNOWLEDGEMENTS}

We thank M. Cashel for spoT mutant strains and for advice, J. B. Sweasy, S. Manning and S. Samuels for helpful criticisms of the manuscript, J. Bernards and J. Reimers for excellent technical assistance, and J. Strange for sequencing and oligonucleotide synthesis. Supported in part by PHS grant GM/ OD54279 (to B.E. W.) from the National Institutes of Health and $\mathrm{AI} 34050$ (to M.F.M.).

\section{REFERENCES}

Ames, B. N. \& Garry, B. (1959). Coordinate repression of the synthesis of four histidine biosynthetic enzymes by histidine. Proc Natl Acad Sci USA 45, 1453-1461.

Ausubel, F. M., Brent, R., Kingston, R. E., Moore, D. D., Seidman, J. G., Smith, J. A. \& Strahl, K. (1989). Short Protocols in Molecular Biology. New York: John Wiley \& Sons.

Blasi, F. \& Bruni, C. B. (1981). Regulation of the histidine operon: translation-controlled transcription termination (a mechanism in common to several biosynthetic operons). Curr Top Cell Regul $19,1-45$.

Burns, R. O., Calvo, J., Margolin, P. \& Umbarger, H. E. (1966). Expression of the leu operon. J Bacteriol 91, 1570-1576.

Cashel, M. \& Rudd, K. E. (1987). The stringent response. In Escherichia coli and Salmonella typhimurium: Cellular and Molecular Biology, pp. 1410-1438. Edited by F. C. Neidhardt, J. L. Ingraham, K. Brooks Low, B. Magasanik, M. Schaechter \& H. E. Umbarger. Washington DC: American Society for Microbiology.

Chung, C. T., Niemela, S. L. \& Miller, R. H. (1985). One-step preparation of competent Escherichia coli: transformation and storage of bacterial cells in the same solution. Proc Natl Acad Sci USA 86, 2172-2175.

Cordaro, J. C. \& Balbinder, E. (1967). An operator constitutive mutation in a mutant for the first structural gene of the tryptophane operon. Bacteriol Proc 15, 51.

Datta, A. \& Jinks-Robertson, S. (1995). Association of increased spontaneous mutation rates with high levels of transcription in yeast. Science 268, 1616-1619.

Davis, B. D. (1989). Transcriptional bias: a non-Lamarkian mechanism for substrate-induced mutations. Proc Natl Acad Sci USA 96, 5005-5009.

Fehr, S. \& Richter, D. (1981). Stringent response of Bacillus stearothermophilus: evidence for the existence of two distinct guanosine $3^{\prime}, 5^{\prime}$-polyphosphate synthetases. J Bacteriol 145, 68-73.

Fiil, N. P., Meyenburg, K. V. \& Friesen, J. D. (1972). Accumulation and turnover of guanosine tetraphosphate in Escherichia coli. J Mol Biol 71, 769-783.

Fitch, F. W. (1982). The challenges to Darwinism since the last centennial and the impact of molecular studies. Evolution 36, 1133-1143.

Friesen, J. D., Fiil, N. P. \& von Meyenburg, K. (1975). Synthesis and turnover of basal level guanosine tetraphosphate in Escherichia coli. J Biol Chem 250, 304-309.

Gallant, J., Margason, G. \& Finch, B. (1972). On the turnover of ppGpp in Escherichia coli. J Biol Chem 247, 6055-6058.

Hanawalt, P. \& Mellan, I. (1993). Stranded in an active gene. Curr Biol 3, 67-69.

Herman, R. K. \& Dworkin, N. B. (1971). Effect of gene induction on the rate of mutagenesis by ICR-191 in Escherichia coli. J Bacteriol $106,543-550$.

Kirino, H., Aoki, M., Aoshima, M., Hayashi, Y., Ohba, M., Yamagishi, A., Wakagi, T. \& Oshima, T. (1994). Hydrophobic interaction at the subunit interface contributes to the thermostability of 3-isopropylmalate dehydrogenase from an extreme thermophile, Thermus thermophilus. Eur J Biochem 220, 275-281.

Lagosky, P. A. \& Chang, F. N. (1980). Influence of amino acid starvation on guanosine $5^{\prime}$-diphosphate $3^{\prime}$-diphosphate basallevel synthesis in Escherichia coli. J Bacteriol 144, 499-508.

Lazzarini, R. A., Cashel, M. \& Gallant, J. (1971). On the regulation of guanosine tetraphosphate levels in stringent and relaxed strains of Escherichia coli. J Biol Chem 246, 4381-4385.

Lea, D. E. \& Coulson, C. A. (1949). The distribution of the number of mutants in bacterial populations. J Genet 49, 264-285.

Lindahl, T. \& Nyberg, B. (1972). Rate of depurination of native deoxyribonucleic acid. Biochemistry 11, 3610-3618.

Lindahl, T. \& Nyberg, B. (1974). Heat-induced deamination of cytosine residues in deoxyribonucleic acid. Biochemistry 13, 3405-3410.

Luria, S. \& Delbrück, M. (1943). Mutations of bacteria from virus sensitivity to virus resistance. Genetics 28, 491-504.

Metzgar, S., Schreiber, G., Alzenman, E., Cashel, M. \& Glaser, G. (1989). Characterization of the relA1 mutation and a comparison of relA1 with new relA null alleles in Escherichia coli.J Biol Chem 264, 21146-21152.

Riggs, D. L., Mueller, R. D., Kwan, H.-S. \& Artz, S. W. (1986). Promoter domain mediates guanosine tetraphosphate activation of the his operon. Proc Natl Acad Sci USA 83, 9333-9337.

Rudd, K. E., Bochner, B. R., Cashel, M. \& Roth, J. R. (1985). Mutations in the spoT gene of Salmonella typhimurium: effects on his gene expression. J Bacteriol 163, 534-542.

Ryan, F. J. (1955). Spontaneous mutation in non-dividing bacteria. Genetics 40, 726-738.

Sambrook, J. E., Fritsch, E. F. \& Maniatis, T. (1989). Molecular Cloning: a Laboratory Manual, 2nd edn. Cold Spring Harbor, NY: Cold Spring Harbor Laboratory. 
Sarubbi, E., Rudd, K. E. \& Cashel, M. (1988). Basal ppGpp level adjustment shown by new spoT mutants affects steady state growth rates and $r r n A$ ribosomal promoter regulation in Escherichia coli. Mol Gen Genet 213, 214-222.

Savic, D. J. \& Kanazir, D. T. (1972). The effect of a histidine operator - constitutive mutation on UV induced mutability with the histidine operon of Salmonella typhimurium. Mol Gen Genet 118, 45-50.

Selby, C. P. \& Sancar, A. (1994). Mechanisms of transcriptionrepair coupling and mutation frequency decline. Microbiol Rev 58, 317-329.

Shand, R. F., Blum, P. H., Mueller, R. D., Riggs, D. L. \& Artz, S. W. (1989). Correlation between histidine operon expression and guanosine $5^{\prime}$-diphosphate- 3 -diphosphate levels during amino acid downshift in stringent and relaxed strains of Salmonella typhimurium. J Bacteriol 171, 737-743.

Siebenlist, U., Simpson, R. B. \& Gilbert, W. (1980). E. coli RNA polymerase interacts homologously with two different promoters. Cell 20, 269-281.

Singer, B. \& Kusmierek, J. T. (1982). Chemical mutagenesis. Annu Rev Biochem 52, 655-693.

Stephens, J. C., Artz, S. W. \& Ames, B. N. (1975). Guanosine 5'diphosphate (ppGpp): positive effector for histidine operon transcription and general signal for amino-acid deficiency. Proc Natl Acad Sci USA 72, 4389-4393.

Stewart, F. M., Gordon, D. M. \& Levin, B. R. (1990). Fluctuation analysis: the probability distribution of the number of mutants under different conditions. Genetics 124, 175-185.

Tracy, T. E. \& Mulcahy, L. S. (1991). A simple method for direct automated sequencing of PCR fragments. BioTechniques 11, $68-75$.

Winkler, M. E., Roth, D. J. \& Hartman, P. E. (1978). Promoter- and attenuator-related metabolic regulation of the Salmonella typhimurium histidine operon. J Bacteriol 133, 830-843.

Winkler, M. E., Zawodny, R. V. \& Hartman, P. E. (1979). Mutation spoT of Escherichia coli increases expression of the histidine operon deleted for the attenuator. J Bacteriol 139, 993-1000.

Wright, B. E. (1996). The effect of the stringent response on mutation rates in E. coli K12. Mol Microbiol 19, 213-219.

Wright, B. E. (1997). Does selective gene activation direct evolution? FEBS Lett (in press).

Xiao, H., Kalman, M., Ikehara, K., Zemel, S., Glaser, G. \& Cashel, M. (1991). Residual guanosine 3',5'-bispyrophosphate synthetic activity of relA null mutants can be eliminated by spoT null mutations. J Biol Chem 266, 5980-5990.

Yanisch-Perron, C., Vieira, J. \& Messing, J. (1985). Improved M13 phage cloning vectors and host strains: nucleotide sequences of the M13mp18 and pUC19 vectors. Gene 33, 103-119.

Received 20 June 1996; revised 30 September 1996; accepted 14 October 1996. 